\title{
STUDIES
}

\section{Teachers' Work with Taxonomy of Educational Objectives as One of the Forms of the Gifted Preschoolers' Development}

\author{
Eva Machů - Petr Lukeš ${ }^{*}$ \\ Received: June 23, 2019; received in revised form: August 31, 2019; \\ accepted: September 2, 2019
}

\begin{abstract}
:
Introduction: The article presents the results of a research project the aim of which was to describe the level of kindergarten teachers' work with educational objectives in connection with the application of a differentiated curriculum for the development of gifted children.

Methods: The research tool was a questionnaire in which the teachers selected one of three answers possible and matched their pedagogical activities in kindergarten the most. 345 teachers from kindergartens in the Czech Republic took part in the research. Data was processed using computer software SPSS.

Results: It was discovered that most of them can differentiate their instructions, however, at least a half of them do not respect the rules of inclusive education and their instructions result in an unwanted labelling of the gifted children. We have also proved that the level of the teachers' work with the educational objectives is positively influenced by their longer than 10 years' experience, work with heterogeneous class age-wise, and their having attended a seminar focused on the topic of giftedness.

Discussion: The discussion focuses on the description of variables affecting the level of work with educational objectives in connection with the application of a differentiated curriculum for the development of gifted children.

Limitations: The limitation is the simplification of the pedagogical reality into 3 possible answers and the artificial metrization of this data. Another problem was that our questionnaire was focused only on selected aspects of pedagogical work with gifted preschoolers, which were related to the curriculum modification and inclusive education. Furthermore, despite the
\end{abstract}

\footnotetext{
* Eva Machů, Tomas Bata University in Zlín, Research Centre of Faculty of Humanities, Zlín, Czech Republic; machu@utb.cz

Petr Lukeš, Tomas Bata University in Zlín, Department of Pedagogical Sciences, Faculty of Humanities, Zlín, Czech Republic; p_lukes@utb.cz
} 


\title{
Acta Educationis Generalis \\ Volume 9, 2019, Issue 3
}

\begin{abstract}
big amount of validly filled in questionnaires (345) the research cannot be considered to be large area survey and the results cannot be generalized.

Conclusions: Gifted children should have the maximal space for the development of their own potential. It is also necessary to increase the teachers' skills to apply the differentiated curriculum with the features of inclusive education in order to develop the giftedness of all the children as much as possible. One of the possibilities is the kindergarten teachers' attendance to educational events on the topic of giftedness, which is one of the variables which significantly influence the quality of their work.
\end{abstract}

Key words: giftedness, gifted child, differentiated education, inclusive education, Bloom's taxonomy of educational objectives.

\section{Introduction and defining the theoretical background}

The topic of gifted preschoolers has started to gain significance since the early 1980s. The rise of the interest was influenced by numerous researchers which managed to prove that children of preschool age, similarly as in the area of certain types of sport and artistic talent, manifest also mental achievements which give evidence of the children's potential ability to perform strongly in the area of intellect in the future (Hertzog, 2008).

In connection with environmental models of giftedness, e.g. Mönk's multifactor model of giftedness (Mönks, 1992), all three external factors (family, school, and peers), which have an essential effect on the manifestation of the features of giftedness start to co-influence the development of giftedness. Aside from the family environment, the influence of kindergarten and the quality of its education begins to rise significantly.

Let us focus on the kindergarten environment and the process of so-called teacher-managed activities in the kindergartens where intentional and purposeful pedagogical activity with children takes place. We are interested whether the teachers develop children's giftedness in a common integrated classroom using differentiated education and whether it has features of inclusive education. In our article, the preschool age is considered to be the period of age from 3 to 6 (7) years old (ISCED 0).

The children whose selected skills and abilities, praised by the sociocultural environment, are quantitatively and qualitatively more developed in comparison with those of their peers, are considered to be gifted children (Heward, 2013; Škrabánková \& Martínková, 2018; Olszewski-Kubilius, 2003). In connection with the preschool age, they used so-called potential definition of giftedness (Sankar-DeLeeuw, 2013) do not presume manifestation of the features of giftedness, but they express the prediction of a potential for an extraordinary achievement. In this period of age, we cannot refer to the child as a gifted child but a child with manifestations of gifted behavior which may lead to future giftedness. 


\section{Acta Educationis Generalis \\ Volume 9, 2019, Issue 3}

Differentiated education of gifted children in kindergarten is the main condition for the development of gifted children. It provides guidance for teachers in addressing children differences in readiness, interest, and learning profile, with the goal of maximizing the capacity of each student (Tomlinson, 2013). Differentiated education should be done on the level of a modified curriculum which meets the gifted children's specific educational needs. It is recommended to modify the content, process, product, environment, and assessment of the curriculum (Riley, 2011; Smith, 2006; Cukierkorn et al., 2007). Modification of the content of education is about using of broad-based topics and problems which will also allow for deep exploration of academic and interest areas. Modification of the process presumes the use of educative methods developing critical, problem-solving and creative thinking. Modification of the product requires qualitatively more developed results of education, where the gifted children have the possibility to achieve the highest educational objective possible. Modification of the environment involves the change in personal relationships, and also the change of space and material. Modification of assessment involves changes in assessing the results of education which is supposed to be motivating and shaping. All the parts of the curriculum are interconnected and influence each other (Taber, Sumida, \& McClue, 2018).

One of the conditions of functional modification of all the aforementioned parts of the curriculum could be the teacher's work with Bloom's taxonomy of educational (cognitive) objectives as one of the most basic conceptions of lesson planning (Tomlinson, 2013). Contribution of Bloom's taxonomy is generally viewed in implications of the means of specification of the educational objectives with regard to the levels of the thought process from simple tasks to complex tasks. Bloom's taxonomy then logically gains its application in the differentiated education in kindergarten.

As mentioned above, lesson planning with the use of Bloom's taxonomy interconnects all the parts of the curriculum for gifted children (Bailey \& Leonard, 1977; Kostelnik, Soderman, \& Whiren, 2004). Let us describe a few specific situations in the preschool education within the teacher-managed activities. For example, within the contents of education, teachers may plan more variants of the task, from the simpler ones to the more complex ones and the children may choose one of them according to their possibilities resulting from their preconceptions (Trávníčková, 2018). Further use may be in planning extra tasks for the children who manage to complete the common task in a shorter time. These extra tasks may come from the higher educative objectives for the gifted children or from the lower objectives for other children. Task planning may have its use in the group work where the teacher offers various types of tasks ranging in difficulty and the gifted children do not have to qualitatively limit themselves in their work. The application of the higher objectives includes also the need for additional didactic tools (PCs, encyclopedias, etc.) in the classroom equipment. 


\section{Acta Educationis Generalis \\ Volume 9, 2019, Issue 3}

Nowadays, the connection between the principles of the care of the gifted children, including the application of Bloom's taxonomy of educational objectives with the requirements of inclusive education (Riley, 2011; Tomlinson, 2013 ) is becoming more and more important. Inclusive education is the activity of placing all children into standard school (so-called mainstream education) which is prepared adequately for it. In the pedagogical praxis, children are not divided into two groups (i.e. the gifted ones and the not gifted ones) but they are in one heterogeneous group. All the participants of the educative process are working towards creating differentiated conditions for the inclusion of all the children into all the activities connected with preschool education (Nind et al., 2013). There are not any more difficult tasks assigned to the gifted children beforehand. The gifted children have an option to choose a task, or they are not given any limits in education. Children who do not manifest any signs of giftedness may try to complete the more difficult tasks according to their skills. In this regard, we may talk about the development of the children's giftedness and not the development of the gifted children (Smith, 2006).

The aim of our study is to find out the level of the teachers' work with the educational objectives, the assessment of which respects the principles of inclusive education, and also to discover how this state is influenced by selected variables connected with the characteristics of the teachers and classes.

There are not enough similar empirical studies. While browsing databases EBSCO, Academic Search Complete and Pro-Quest Central, we have found studies exploring the modifying strategies of elementary school teachers for gifted children from 5 to 11 years. The outputs of studies, Westberg and Daoust (2004), Akalin et al. (2014) and Van Tassel-Baska and Stambaugh (2005), report that relatively few teachers were modifying their classroom instructions for the children identified as gifted in regular classrooms.

\section{Methodology}

\subsection{The objectives and hypotheses}

The objective of the quantitative research was to map the level of kindergarten teachers' work with educational objectives in connection with the application of differentiated curriculum for the development of children's giftedness. The subobjective was to discover the highest and lowest assessed items of the questionnaire, and to find out whether the total sum of points achieved in the questionnaire is connected with the selected characteristics of the teachers and their classes (length of experience, teacher's attendance to courses of further education focused on the topic of giftedness, the amount of children in classes, types of classes - homogeneous or heterogeneous age-wise). These demographic items were subsequently extracted to 2 statements $\mathrm{H} 1-\mathrm{H} 2$ and 2 hypotheses $\mathrm{H} 3$ - H4: 


\section{Acta Educationis Generalis \\ Volume 9, 2019, Issue 3}

H1: The level of the kindergarten teachers' work with educational objectives improves with the length of their experience.

$\mathrm{H} 2$ : The level of kindergarten teachers' work with the educational objectives improves with a smaller class.

H3: Teachers teaching in heterogeneous classes age-wise manifest a higher level of work with educational objectives than the teachers teaching in homogeneous classes age-wise.

H4: The teachers who were intentionally lectured on the topic of giftedness manifest a higher level of work with the educational objectives than the teachers who were not lectured.

\subsection{Data collection instrument}

We used our own six-item questionnaire (in addition to the demographical data) which are focused on the research problem. These items, aimed at teachers' work with educational objectives, were taken out from a more extensive questionnaire. The original questionnaire as a whole was validated in the past using exploratory factorial analysis and manifests an acceptable reliability $(\alpha=0,77)$ (in detail in Machů \& Kočvarová, 2013). The main items of the questionnaire are to be seen in Table 1 .

The items of the questionnaire were focused on finding out the level of the teachers' work with Bloom's taxonomy of educational objectives through all the aforementioned curriculum modifications.

Each of the items of the questionnaire offered three different solutions for practical application example of differentiated curriculum in controlled activities in education of preschoolers:

- One of the options represented an inadequate solution, as it was not in accordance with specific educational needs of gifted children and did not offer the possibility of curriculum modification (respondents earned 0 points in case of choosing this one).

- Another option was a compromise solution, where teachers used limited possibilities of curriculum modification and thus developed children's giftedness, but they did not respect the principles of inclusive education (1 point). Gifted children were labeled, significantly preferred, or rejected in comparison with the rest of children.

- Another option was considered as showing ideal approach towards care for gifted children in terms of our criteria for differentiated curriculum (2 points). 


\section{Acta Educationis Generalis \\ Volume 9, 2019, Issue 3}

Table 1

The main questionnaire items with marked amounts of achievable points for each item (source: authors)

1 a) Concerning controlled activities in education, all the children are treated in the same way. I lower the requirements for quality or quantity of fulfilling the tasks only for the disadvantaged children. $(0 \mathrm{p})$

b) Concerning controlled activities, I offer to children various tasks (with simpler and more difficult variants) related to the topic of education. Children have the possibility to choose from the simpler or more difficult ones. ( $2 \mathrm{p}$ )

c) Concerning controlled activities, I offer to children various tasks with simpler and more difficult variants related to the topic of the education. The bright and gifted children are given the more difficult task. (1 p)

2 a) During teacher-managed activities, children work together in such a way that none of them is handicapped in any way. If one of the more gifted children finishes the task more quickly, they have the possibility to help the younger children or the children with lower skills. ( $0 \mathrm{p})$

b) If one of the children finishes a task during teacher-managed activities more quickly, they have the possibility to work on an additional task. More gifted and smarter children work on the additional task, sometimes even the children with lower skill levels. (2 p)

c) If one of the children finishes a task during teacher-managed activities more quickly, they have the possibility to work on an additional task. Mostly more gifted and smarter children work on these tasks. (1 p)

3 a) If any of the children finishes the controlled activity earlier than the other children, the teacher motivates the child to work on another, more challenging topic. $(0 \mathrm{p})$

b) If any of the children finishes the controlled activity earlier than the other children, he/she can dedicate time to own activities, on which he/she usually works during free activities (e.g. reading books, use a PC). (1 p)

c) If any of the children finishes the controlled activity earlier than the other children, the teacher motivates the child to work on a more challenging task related to the same topic. $(2 \mathrm{p})$

4 a) During teacher-managed activities, I use group work for developing gifted and smarter children only rarely. These children are bored or complete all the tasks for all the other children. For the gifted children, individual work is the most appropriate so they are not disturbed by the others. $(0 \mathrm{p})$

b) During teacher-managed activities, I use group work for developing the giftedness of children. Most often I group the children according to their level of giftedness and skills. This way, I intentionally create groups of more gifted and smarter children who are assigned more difficult tasks than the other groups. (1 p)

c) During teacher-managed activities, I use group work for developing the children's giftedness. I create not only groups varied by their level of efficiency where I offer individualized activities (activities of various difficulty), but also 


\section{Acta Educationis Generalis \\ Volume 9, 2019, Issue 3}

groups consisting only from more gifted and smarter children, who are then offered more difficult tasks. (2 p)

5 a) During group work, children have their roles (individual tasks). The gifted ones and the smarter ones are assigned more difficult tasks. $(1 \mathrm{p})$

b) During group work, children have their roles which are differentiated according to their difficulty. The gifted ones and the smarter ones may work on more difficult tasks. (2 p)

c) I understand group work as assigning one task to the whole group. All the children work together on one task. $(0 \mathrm{p})$

6 a) The kindergarten has few didactic tools for the development of children's giftedness (children encyclopedias, atlases, children literature, computer, etc.). $(0 \mathrm{p})$

b) The kindergarten is well equipped with didactic tools for the development of children's giftedness. These tools may be used by all the children from the class or school. $(2 \mathrm{p})$

c) The kindergarten is quite well equipped with didactic tools for the development of children's giftedness. These items are used by the gifted children for whom these tools are intentionally meant. (1 p)

The content of the questionnaire was consulted with professionals in this field, as well as with teachers with practice. It was emphasized that the questionnaire should not contain any options prompting the answers with the highest number of points.

The obtained data were processed using computer software SPSS.

\subsection{Research sample}

345 teachers from kindergartens in Zlín and South Moravia regions in the Czech Republic took part in the research. All interviewees were women. Other characteristics of teachers are presented in more detail in the results.

\section{Results}

The first sub-objective was to find out how the questionnaire as a whole held up and to find out the highest and lowest assessed items. The teachers could gain 0 , 1 , or 2 points for each item. For six items, the teachers could gain and gained from 0 to 12 points. The average gained was 6.45 points.

The following table shows the results for each individual item of the questionnaire from the lowest to the highest assessed. Using the chi-squared test, we found out the frequency of the answers which were statistically significantly different from the other selected items. The frequencies marked * have the value of significance 0.01 and the frequencies marked $* *$ have the value of 0.05 . 


\section{Acta Educationis Generalis \\ Volume 9, 2019, Issue 3}

\section{Table 2}

The results for the individual questionnaire items from the lowest to the highest assessed (source: authors)

\begin{tabular}{lllllll}
\hline Item number: & \multicolumn{1}{c}{5} & \multicolumn{1}{c}{2} & \multicolumn{1}{c}{3} & \multicolumn{1}{c}{1} & \multicolumn{1}{c}{4} & \multicolumn{1}{c}{6} \\
\hline 0 point & $131(38 \%)$ & $122(35 \%)$ & $139(40 \%)$ & $98(28 \%)$ & $84(24 \%)$ & $65(19 \%)$ \\
1 point & $83 *(24 \%)$ & $100(29 \%)$ & $56 *(16 \%)$ & $139 * *(40 \%)$ & $111(32 \%)$ & $81(23 \%)$ \\
& & & & & & \\
2 points & $125(36 \%)$ & $117(34 \%)$ & $143(41 \%)$ & $105(30 \%)$ & $144(42 \%)$ & $195 *(57 \%)$ \\
Missing data & 6 & 6 & 7 & 3 & 6 & 4 \\
Average & 0.98 & 0.99 & 1.01 & 1.02 & 1.18 & 1.38 \\
\hline
\end{tabular}

The lowest assessed item was item no. 5 which focused on group work. Almost $60 \%$ of teachers plan the tasks according to different levels of taxonomies of educational objectives, but $24 \%$ of them give these tasks intentionally only to the gifted children which we do not consider to be appropriate with regard to the principles of inclusive education.

Almost the same average score (0.99) had item no. 2 which focused on planning tasks for the children who finish more quickly during common activities. $63 \%$ of teachers plan these "extra activities" but again only $29 \%$ of them give these tasks intentionally only to the gifted children, which according to our theoretical basis lead to unwanted labelling of gifted children. Other teachers (35\%) do not create these types of activities for children and do not differentiate in this area.

Another questionnaire item with the average of 1.01 was item no. 3 which focused on planning tasks for the children who finish more quickly during common activities, however, this time from another point of view. Almost $40 \%$ of teachers motivate the children who finish more quickly to work on their own activities which have nothing in common with the topic of the main common activity (work with PC, free play), even though it is education within the mainframe of the teacher-managed activity. With regard to the theoretical basis, we do not consider this strategy to be appropriate because the teacher does not differentiate. Other teachers $(57 \%)$ create "extra tasks" and thus differentiate. However, almost $16 \%$ of them use an acceleration program in which the child is offered a developing activity within the mainframe of another topic, which supports permanent labelling of the gifted children. However, a relatively high amount of teachers (41\%) use an appropriate type of enrichment which deepens the child's knowledge in the mainframe of the current topic.

Item no. 1 got the average of 1.02 and it was focused on the offer of the tasks of different levels of difficulty (i.e. on more levels of Bloom's taxonomy). $28 \%$ of teachers do not differentiate the tasks for the children. The rest (70\%) 


\section{Acta Educationis Generalis \\ Volume 9, 2019, Issue 3}

differentiate, most of them (40\%), however, gives the more difficult tasks within the mainframe of the topic intentionally only to the gifted children which again supports the labelling of the gifted children.

The following item no. 4 got the average of 1.18 and it was focused on dividing children during group work and giving differentiated tasks. 24\% of the teachers claim that they use group work rarely, which is, with regard to the phrasing of the question may be related to the fact that they do not differentiate during the education. $32 \%$ of the teachers differentiate during group work by preferring to have the groups consist of the same level of the children's giftedness. Most of the teachers $(42 \%)$ declare, however, that they create differentiated groups efficiency-wise and use differentiated tasks for the children in these groups.

The highest assessed item no.6 was focused on creative activities. 19\% of teachers admit that they offer the children pre-prepared tools which the children subsequently finish which, in our opinion, is not connected with creativity. 23\% of teachers create an opportunity for free creativity only for the gifted children. Most of the teachers (57\%) declare that they provide freedom during creative activities for all the children.

The next objective was to find out whether the total sum of the points achieved in the questionnaire is connected with the selected characteristics of the teachers. Therefore, we stated the H1: The level of the kindergarten teachers' work with educational objectives improves with the length of their experience. In the questionnaire, the length of experience was divided as follows: beginners (4 or fewer years of experience), intermediate (5 to 10 years of experience) and experts (11 and more years of experience). Using the Kurskal-Wallis test with multiple comparison of p-values, we found out that there is a significant difference between the levels of the teachers' work with educational objectives in connection with the length of their experience. While the level of beginners and intermediate teachers do not differ (sign. = 1), the expert group is significantly more successful than the previous groups regarding the value of significance 0.05 in comparison with the beginners (sign. $=0.019$ ) and the value of significance 0.01 in comparison with the intermediate group (sign. $=0.004$ ). $\mathrm{H} 1$ was proved (but only with teachers with the length of experience of more than 10 years).

Table 3

Comparison of p-values and point average (source: authors)

\begin{tabular}{lllll}
\hline $\begin{array}{l}\text { Teacher's } \\
\text { experience length: }\end{array}$ & Beginners & Intermediate & Experts & $\begin{array}{l}\text { Point } \\
\text { average }\end{array}$ \\
\hline Beginners & - & 1.000000 & 0.018668 & 5.939394 \\
Intermediate & 1.000000 & - & 0.004440 & 6.057377 \\
Experts & 0.018668 & 0.004440 & - & 6.987261 \\
\hline
\end{tabular}




\section{Acta Educationis Generalis \\ Volume 9, 2019, Issue 3}

We also wanted to discover the relationship between the application of the higher levels of educational objectives and the size of the class which was divided into a smaller class ( 15 children or fewer) and a bigger class ( 16 children or more). We stated statement $\mathrm{H} 2$ : The level of kindergarten teachers' work with the educational objectives improves with a smaller class. Using the MannWhitney U-Test, we found out that there is not a more significant difference with regard to the size of the class /sign. $=0.897)$. The hypothesis was not proved. Average results of both groups compared are shown in table no. 4 .

Table 4

Comparison of average points gained by teachers from smaller or bigger classes (source: authors)

\begin{tabular}{lll}
\hline Size of class: & Point average & SD \\
\hline Smaller class & 6.500000 & 2.500943 \\
Bigger class & 6.450172 & 2.552907 \\
\hline
\end{tabular}

We were also interested whether there is a relationship between the teachers' work and the fact that they work with an age-wise homogeneous group of children (a class with children of a similar age) or mixed (a class with children of various ages). We stated hypothesis $\mathrm{H} 3$ : Teachers teaching in heterogeneous classes age-wise manifest a higher level of work with educational objectives than the teachers teaching in homogeneous classes age-wise. Using the MannWhitney U-test, we found out that there is a significant difference in the value of significance 0.001 (sign. $=0.002$ ) with regards to the type of class. The hypothesis was proved. The teachers teaching in the age-wise heterogeneous classes show better results in comparison with the teachers teaching in age-wise homogeneous classes. The results are shown in table no. 5 .

Table 5

Comparison of average points gained by teachers working with homogeneous or heterogeneous class age-wise (source: authors)

\begin{tabular}{lll}
\hline Type of class : & Point average & $S D$ \\
\hline Age-wise homogeneous class & 6.033898 & 2.418908 \\
Age-wise heterogeneous class & 6.903614 & 2.610536 \\
\hline
\end{tabular}




\section{Acta Educationis Generalis \\ Volume 9, 2019, Issue 3}

The last comparison of the level of the teachers' work with educational objectives was done according to the fact whether they were intentionally acquainted with the topic of the giftedness, i.e. whether they attended lectures on the topic of giftedness or not. We stated hypothesis H4: The teachers who were intentionally lectured on the topic of giftedness manifest a higher level of work with the educational objectives than the teachers who were not lectured. For the testing, we used Mann-Whitney U-test again. The relationship was confirmed with the value of significance 0.05 (sign. $=0.014$ ). Hypothesis $\mathrm{H} 4$ was proved.

Table 6

Comparison of average points gained by teachers who were lectured or not (source: authors)

\begin{tabular}{lll}
\hline $\begin{array}{l}\text { Teachers' attendance } \\
\text { on lectures: }\end{array}$ & Point average & SD \\
\hline Non-lectured teachers & 6.202765 & 2.641442 \\
Lectured teachers & 6.943548 & 2.317492 \\
\hline
\end{tabular}

\section{Summary and discussion}

The first sub-objective was to discover the highest and lowest assessed items of the questionnaire describing the level of kindergarten teachers' work with the educational objectives in connection with the application of differentiated curriculum for the development of children's giftedness. As we have written in the theoretical basis, differentiation via application of Bloom's taxonomy of educational objectives runs through the whole curriculum. In our questionnaire, we focused more on the content (items 1, 2, 3,6) and process (mainly group work, items 4, 5). Generally, it cannot be stated what the level of teachers' work with the educational objectives is, it depends on the curricular context.

The items of the questionnaire were evaluated according to the criteria stated in the theoretical basis. There were three possible answers in each questionnaire item, marked with $0-1-2$ points. In six items, the teachers could gain from 0 to 12 points. On average, they gained 6.45 points which we do not consider to be a successful result.

First, let us comment on the curriculum. The highest assessed item was no. 6 . Most of the teachers declared that during creative activities, all their children are given freedom in their work. Item no. 1 specified this problem. We found out that most of the teachers offer various alternative tasks to the children, but the more difficult tasks are meant for the gifted children only. These teachers differentiate, but not in concordance with inclusive education. Items no. 2 and 3 also focused on the content of the curriculum. Specifically, they focused on 


\section{Acta Educationis Generalis \\ Volume 9, 2019, Issue 3}

planning of activities for children who finish with tasks more quickly. It was found out that $35 \%$ of teachers do not differentiate and do not motivate children. The same number of teachers offer these children additional tasks which match their skills and abilities. Furthermore, $40 \%$ of teachers admit that the children who finished an activity earlier go on to work on their own activities which are not connected with the topic of the teacher-managed activity. The same number of teachers claim that they motivate the children to work on a more difficult task which builds on the topic of the main activity.

The other items focused on process and management of group work. On average, item no. 5 was assessed the lowest. $38 \%$ of the teachers declared that they do not differentiate group work. On the contrary, item no. 4 , where $42 \%$ of the teachers claimed that they regularly created mixed groups efficiency-wise which were offered individualized activities, was assessed positively.

Another sub-objective was to find out whether the total sum of points in the questionnaire is connected with the selected characteristics of teachers and their classes. The following table summarizes the results of the hypotheses tested.

Table 7

Summarizing the results (source: authors)

\begin{tabular}{ll}
\hline Hypothesis (and statements): & Result: \\
\hline H1: The level of the kindergarten teachers' & $\begin{array}{l}\text { Statement was proved, but } \\
\text { work with educational objectives improves } \\
\text { only with teachers with the } \\
\text { with the length of their experience. }\end{array}$ \\
& $\begin{array}{l}\text { length of experience of more } \\
\text { than 10 years. }\end{array}$
\end{tabular}

H2: The level of kindergarten teachers' Statement was not proved. work with the educational objectives improves with a smaller class.

H3: Teachers teaching in heterogeneous Hypothesis was proved. classes age-wise manifest a higher level of work with educational objectives than the teachers teaching in homogeneous classes age-wise.

H4: The teachers who were intentionally lectured on the topic of giftedness manifest a higher level of work with the educational objectives than the teachers who were not lectured. 


\section{Acta Educationis Generalis \\ Volume 9, 2019, Issue 3}

By testing the hypotheses, we managed to verify the variables which influence positively the level of quality of the teachers' work with educational objectives and differentiating instructions. They are the further education of the teachers on the topic of giftedness and education in heterogeneous groups age-wise. It is logical that the teacher whose class consists of children of different ages faces situations which require differentiation on a daily basis will manage work with educational objectives well.

We have also identified the variables which despite our theoretical basis do not influence the level of application of differentiated instructions. In the case of $\mathrm{H} 1$, it is the length of experience which is often in some empirical situations viewed as an unquestionable prerequisite for expertness (Ericsson, 2006). The study of D. J. Palmer et al. (2005) which analyzed 27 studies of teacher expertness found out that for achieving expertness, experience of 5-10 years in the field is required. The teachers from our research who manifested a statistically higher quality level of work had length of experience of 10 years and more. This corresponds to Ericsson (2006) who stated that it is required to view not only the length of experience but also the context, such as focus of experience, staying in one workplace for longer than 3 years, membership in a professional group, etc. In the case of $\mathrm{H} 2$, we defined another variable - the number of children in a class which, despite our assumption and theoretical background, does not influence the level of application of differentiated instructions.

After we presented our findings, it is also needed to point out the limitations connected with the conducted research. The biggest limitation which was manifesting during the whole research is, in our opinion, the simplification of the pedagogical reality into 3 possible answers evaluated with 0,1 and 2 points and the artificial metrization of this data. We are aware that all the measuring in education and also in other areas, is considered to be relative, simplifying and serves the paradigm which we do through the evaluation of the teachers' answers. Another problem was that our questionnaire was focused only on selected aspects of pedagogical work with gifted preschoolers, which were related to the curriculum modification and inclusive education. Furthermore, despite the big amount of validly filled in questionnaires (345) the research cannot be considered to be large area survey and the results cannot be generalized.

We are also aware that the teachers may have described the application of their educational strategies in the questionnaire to be better than it is in reality. On the other hand, we can look at the results of the research not only from the viewpoint of what educational strategies the teachers use but also which strategies the teachers think are suitable for the development of the children' giftedness. 


\section{Acta Educationis Generalis \\ Volume 9, 2019, Issue 3}

\section{Conclusions}

Preschool age is a period which has an essential role in the development of giftedness. In this age, child gets their first experience with intentional education and comes into contact with first educational, working, and also social habits in connection with the development of their giftedness. Gifted children can be unintentionally excluded from the community of children and, therefore, become labelled, but they should have the maximal space for development of their own potential. It is also necessary to increase the teachers' skills to apply the differentiated curriculum with the features of inclusive education in order to develop the giftedness of all the children as much as possible. One of the possibilities is the kindergarten teachers' attendance to educational events on the topic of giftedness, which is one of the variables which significantly influence the quality of their work.

\section{Acknowledgements}

The article has been produced with the support of the project IGA (IGA/FHS/2019/001) at Faculty of Humanities, Tomas Bata University in Zlín.

\section{References}

Akalin, S., \& Demir, S. et al. (2014). The needs of inclusive preschool teachers about inclusive practices. Eurasian Journal of Educational Research, 54, 39-60.

Bailey, D. B., \& Leonard, J. (1977). A model for adapting. Bloom's taxonomy to a preschool curriculum for the gifted. Gifted Child Quarterly, 21(1), 97103.

Cukierkorn, J. R., Karnes, F. A., \& Manning, S. (2007). Serving the preschool gifted child: Programming and resources. Roeper Review, 29(4), 271-276.

Ericsson, K. A. (2006). The influence of experience and deliberate practice on the development of superior expert performance. In K. A. Ericsson et al. (Eds.), The Cambridge Handbook of Expertise and Expert Performance (pp. 683-704). Cambridge: Cambridge University Press.

Hertzog, N. B. (2008). Early Childhood Gifted Education. Texas: Prufrock Press Inc.

Heward, W. L. (2013). Exceptional Children. An Introduction to Special Education. Ohio: Pearson.

Kostelnik, M. J., Soderman, A. K., \& Whiren, A. P. (2004). Developmentally Appropriate Curriculum: Best Practices in Early Childhood Education. NJ: Pearson.

Machů, E., \& Kočvarová, I. (2013). Kvalita školy z hlediska péče o nadané žáky. Zlín: UTB ve Zlíně. 


\section{Acta Educationis Generalis \\ Volume 9, 2019, Issue 3}

Mönks, F. J. (1992). Development of gifted children: The issue of identification and programming. In F. J. Mönks., \& W. A. M. Peters (Eds.), Talent for the Future. Proceedings of the Ninth World Conference on Gifted and Talented Children (pp. 191-202). Assen: Van Gorcum.

Nind, M., Rix, J., Sheehy, K., \& Simmons, K. (2013). Curriculum and Pedagogy in Inclusive Education. London and New York: Routledge.

Olszewski - Kubilius, P. (2003). Early Gifts - Recognizing and Nurturing Children's Talents. Texas: Prufrock Press.

Palmer, D. J., Stough, L. M., Burdnski, T. K., \& Gonzales, M. (2005). Identifying teacher expertise: An examination of researchers' decision making. Educational Psychologist, 40(1), 13-25.

Riley, T. L. (2011). Teaching Gifted Students in the Inclusive Classroom. USA: Prufrock.

Sankar - DeLeeuw, N. (2013). Gifted preschoolers: Parent and teacher views on identification, early admission and programming. Roeper Review, 21(3), 174-179.

Smith, C. M. M. (2006). Principles of inclusion: Implications for able learners. In C. M. M. Smith (Ed.), Including the Gifted and Talented. Making Inclusion Work for More Gifted and Able Learners (pp. 3-21). London: Routledge.

Škrabánková, J., \& Martínková, M. (2018). Giftedness as a possible risk of bullying. Acta Educationalis Generalis, 8(3), 69-93. https://doi.org/10.2478/atd-2018-0018

Taber, K. S., Sumida, M., \& Mcclue, L. (2018). Teaching Gifted Learners in STEM Subjects. NY: Routledge.

Tomlinson, C. A. (2013). Differentiated instruction. In C. M. Callahan, \& H. L. Herberg-Davis (Eds.), Fundamentals of Gifted Education, Considering Multiple Perspectives (pp. 287-300). NY: Routledge.

Trávníčková, P. (2018). An analysis of teacher's didactical activity in the context of children's preconception usage. Acta Educationalis Generalis, 8(2), 40-53. https://doi.org/10.2478/atd-2018-0010

Van Tassel-Baska, J., \& Stambaugh, T. (2005). Challenges and possibilities for serving gifted learners in the regular classroom. Theory into Practice, 44, 211-217.

Westberg, K., \& Daoust, M. E. (2004). The Results of the Classroom Practices Survey Replication in Two States. Connecticut: The National Research Center on the Gifted and Talented. 